\title{
The dietary intake of a group of vegetarian children aged 7-11 years compared with matched omnivores
}

\author{
BY INDIRA NATHAN ${ }^{1}$, ALLAN F. HACKETT' ${ }^{1}$ AND SIMON KIRBY \\ ${ }^{1}$ School of Education and Community Studies and ${ }^{2}$ School of Computing and Mathematical \\ Sciences, Liverpool John Moores University, IM Marsh Campus, Barkill Road, \\ Liverpool L17 6BD
}

(Received 2 October 1994 - Revised 6 June 1995-Accepted 4 July 1995)

\begin{abstract}
There is a lack of information concerning the diet of vegetarian children. The present study compared the dietary intake of fifty vegetarian children, aged 7-11 years, with fifty matched omnivores. Three $3 \mathrm{~d}$ food records were completed by each child at intervals of 6 months. The day after completing the record each child was interviewed to clarify food items and assess portion sizes. Food records were analysed using Microdiet (University of Salford). Finger-prick cholesterol and haemoglobin measurements were taken from a subsample of the group. Only one child's family was a member of the Vegetarian Society and almost one-third of vegetarian children had omnivorous parents (seventeen of fifty subjects). The energy intake (MJ) of the vegetarians was significantly lower than that of the omnivores, 7.6 (SD 1.05) and 8.0 (SD 1.36) respectively; there were no significant differences in Fe or fat intakes. For the vegetarians polyunsaturated: saturated fat ratio (P:S 0.7 (SD 0.04)) and NSP intake (13.8 (SD 0.7) g/d) were significantly higher than those of the omnivores (P:S 0.5 (SD 0.02), NSP 10.3 (SD 0.4) g/d). There was no significant difference in cholesterol measurements $(\mathrm{mmol} / \mathrm{l})$ between the two groups: vegetarian 3.5 (SD 0.12), omnivores 3.7 (SD 0.15). The haemoglobin level (g/l) of the vegetarians (11.8 (SD 0.2)) was significantly below that of the omnivores $(12.4$ (SD 0.2)); $47.5 \%$ of the vegetarian children fell below the third percentile of the Dallman reference curves (Dallman \& Siimes, 1979). The intake of the vegetarians more closely resembled current recommendations (Department of Health, 1991), although they need to be as aware as omnivores of the need to reduce fat intake. The haemoglobin levels of vegetarian children suggest that they need dietary advice to ensure optimal absorption of Fe.
\end{abstract}

Dietary intake: Vegetarian children

There is a dearth of information regarding the dietary intake of vegetarian children. The few studies have focused on preschool children from organized vegetarian groups such as members of communes, Seventh Day Adventists (SDA) and those who follow a macrobiotic diet (Roberts Fulton et al. 1980; Van Staveren \& Dagnelie, 1988; Sabate et al. 1991) and, hence, little is known about the diet and nutritional status of moderate 'independent' vegetarian children in the UK.

Preschool lacto-ovo-vegetarian children (LOV) have been reported to have higher NSP and lower vitamin D, fat and energy intakes than omnivores (Van Staveren \& Dagnelie, 1988). An early study of adolescent vegetarians reported lower energy, protein and $\mathrm{Fe}$ intakes than those of omnivores, although recommended intakes for all nutrients were met (Hardinge \& Stare, 1954). There is little further data regarding the nutritional intake of LOV. Children following macrobiotic and vegan diets have been reported to have low intakes of energy, fat, protein, vitamin $\mathrm{B}_{12}$, vitamin $\mathrm{D}, \mathrm{Ca}$ and $\mathrm{Fe}$. The ability of these restricted diets to meet requirements, especially during the preschool years, has been questioned (MacLean \& Graham, 1980; Jacobs \& Dwyer, 1988). 
Nutritional deficiencies reported amongst vegetarian children have included rickets (Dwyer et al. 1979; Curtis et al. 1983; Hellebostad et al. 1985), anaemia (Dwyer et al. 1982; Dagnelie et al. 1989), vitamin $B_{12}$ deficiency (Specker et al. 1990) and lower than expected blood Zn levels (Smit-Vanderkooy \& Gibson, 1987). These deficiencies, however, have been reported only in children following the most restricted vegetarian diets. In addition, diets described as 'vegetarian' have been associated with slightly restricted growth (Kaplan \& Toshima, 1992). In contrast, SDA vegetarian children appear to have adequate nutritional intakes (Sabate et al. 1991).

Despite the lack of information, the need for a vegetarian diet to be well-planned has been stressed, indicating professional concern (British Dietetic Association, 1995; American Dietetic Association, 1988). However, many possible health benefits of a vegetarian diet have been documented amongst adults, including a lower incidence of cancer and heart disease (Thorogood et al. 1994). It is not known whether vegetarian children can also expect to enjoy such benefits, that is whether a vegetarian diet in childhood can lay the foundations for reductions in adult morbidity and mortality. Other non-diet-related factors may be influencing the health of vegetarian adults.

The main aim of the present paper is to compare the dietary intake of vegetarian children with that of omnivores and with current recommendations (Department of Health, 1991).

\section{METHODS \\ Subjects}

Subjects were recruited in the Liverpool area by advertising in health food shops, vegetarian society publications and a Hindu temple and with the help of school nurses and head teachers. Criteria for inclusion were that the child was healthy, aged 7-10 years and had followed a vegetarian diet for at least 3 months. A vegetarian diet was defined as one that may include dairy products, eggs and fish, but not meat or meat products. Healthy was defined as having no history of serious illness likely to affect growth or diet.

Each vegetarian child was asked to introduce to the study an omnivorous friend of the same age, ethnic group and sex. In this way it was hoped to obtain a control group closely matched for a variety of physical and social factors. The dietary intake and growth of each matched pair of children were measured for 1 year, all data being collected from the children in their homes. (The growth data will be published elsewhere.) Each family was interviewed using a structured questionnaire to obtain information regarding social class (occupation of head of household and house and car ownership), and the health-related behaviour of parents and child (smoking, visits to doctor and dentist and amount of exercise per week). In addition, children were questioned about their leisure-time activities. Having completed the study of diet and growth, the children were asked to volunteer to give a finger-prick blood sample to determine non-fasting total cholesterol and haemoglobin levels.

\section{Dietary assessment}

Nutrient intake was assessed using a $3 \mathrm{~d}$ dietary diary and interview and calibrated food models (Hackett et al. 1983; Adamson et al. 1992; Moynihan et al. 1995). Each pair of children was asked to fill in a pocket-sized diary on three occasions at 6-month intervals. Each record included one weekend day and all data were collected between January 1992 and July 1993 by I.N. Subjects were visited on the day before the recording period for instruction on how to complete the food diary. They were re-visited on the fourth day and, during a $20 \mathrm{~min}$ interview (with child and parent(s)), dietary information was clarified and food portion sizes determined using food models. When possible, interviews were 
conducted in the kitchen to identify utensils used and food wrappers and packets were often available. The information was coded using food tables (Holland et al. $1991 \mathrm{~b}$ ) and all available supplements (Tan et al. 1985; Holland et al. 1988, 1989, 1991a, 1992a,b) and analysed using Microdiet (University of Salford, 1993). The mean nutrient intake of each individual was expressed as a percentage of the appropriate reference nutrient intake (RNI) and lower reference nutrient intake (LRNI; Department of Health, 1991) and mean values calculated.

The following food groups were used to examine the contribution of foods to intake of particular nutrients: breakfast cereals; breads, including chapattis and pitta bread; puddings, biscuits and cakes, including ice-cream, fruit yoghurts, teacakes, scones and crumpets; dairy products, including natural yoghurt and cheese (unless a separate value is given for cheese); confectionery, including iced lollies and chocolate bars; meat, including meat products (includes associated pastry); soft drinks, including all fizzy drinks, fruit juice and squash; fruit, including fresh and tinned fruit; vegetables, excluding chips and crisps, but including beans unless a value is given for beans; convenience foods, including vegeburgers, pizza, vegebanger, quiche, nut roast, ready-made meals, e.g. vegetable lasagne, vegetable pasty and vegetable pie; nuts, including peanut butter.

BMR was calculated using the appropriate equations for age and sex for each child (Schofield et al. 1985) and compared with estimates of energy intake.

\section{Haemoglobin and cholesterol measurements}

No subject had cyanotic or cold fingers but slight pressure was usually required at some distance from the skin-prick to establish blood flow and the first few drops of blood were discarded. The Hemocue system (Hemocue Ltd, Sheffield) was used to determine haemoglobin. The microcuvette $(10 \mu \mathrm{l})$ was filled directly from the subject's finger and a reading obtained immediately. Anaemia was defined as a haemoglobin concentration below the third percentile (Dallman \& Siimes, 1979). The total blood cholesterol level was determined using the Reflotron method (Boehringer Mannheim, Germany). A $30 \mu \mathrm{l}$ capillary tube was filled with blood from a finger-prick and pipetted onto a Reflotron reagent strip.

Data were analysed using Statistical Package for the Social Sciences (1992). The paired $t$ test was used to determine whether the mean dietary differences differed from zero. The questionnaire data were analysed using the McNemar test to assess differences in proportions of replies.

Ethical permission for the present observational study of diet and growth was granted by the Liverpool John Moores University Ethical Committee. All parents and subjects gave their written informed consent to participation.

\section{RESULTS}

\section{Subjects}

Sixty-three vegetarian subjects volunteered for the study but only fifty-two found a suitable meat-eating friend. Subsequently two vegetarians began eating meat and were excluded from the analysis. Twenty-three vegetarian subjects ate fish, their mean fish consumption (g/person per d) being 10.3 (range $0-37$, median 6.7 ). On entry to the study all other vegetarians were LOV and $86 \%$ of subjects had been vegetarian for over 1 year (Table 1 ). During the project one LOV became vegan. Just over two-thirds of the vegetarians came from families where the mother was vegetarian (Table 1) but only twenty-three had vegetarian fathers. No family had a vegetarian father and omnivorous mother and only one family were members of the Vegetarian Society. 
Table 1. The period of time during which the 7-11-year-old vegetarian subjects and their parents from the Liverpool area have followed a vegetarian diet*

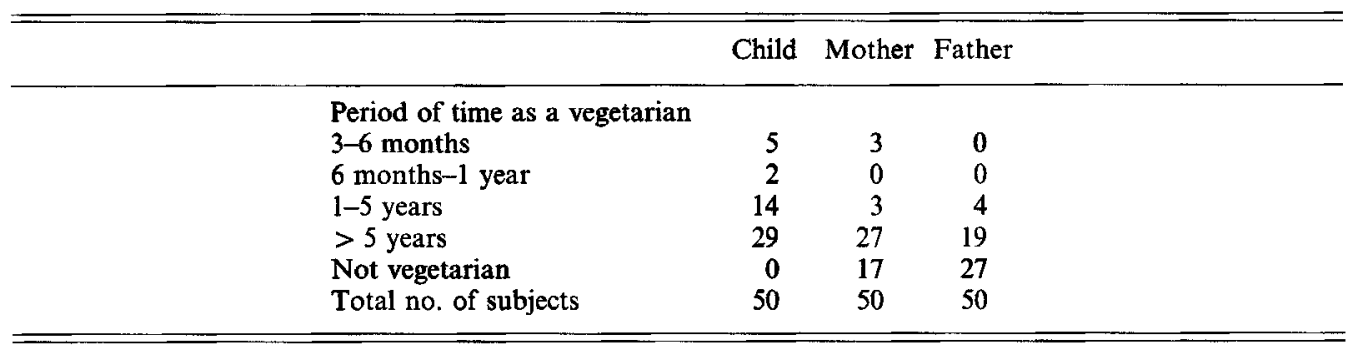

* For details of subjects and procedures, see pp. 534-535.

Subjects were closely matched for age (mean age (years): vegetarians 9.1 (SD 1.5), omnivores 9.4 (SD 1.4)), sex (twenty-nine female pairs, twenty-one males), race (two pairs of Hindu children took part) and socio-economic group. The sample was skewed with twenty-six pairs from socio-economic groups I and II (Registrar General, 1991). Four vegetarians and eight omnivores were from single-parent families. The parents of both groups were similarly aged (years; mothers: vegetarians 38.4 (SD 5.5), omnivores $38 \cdot 8$ (SD 4.9); fathers: vegetarians 39.9 (SD 5.5), omnivores 41.0 (SD 5.6)). There were no differences between the vegetarian and omnivorous families regarding use of medical services, health-related behaviour or number of siblings. In particular, there were no differences in the number of parents who smoked (mothers: twelve vegetarian, fourteen omnivore; fathers: nine vegetarian, fourteen omnivore). The only differences between the two groups were that vegetarian children were less likely to have been bottle-fed (vegetarians five of fifty subjects, omnivores eighteen of fifty subjects; $P=0.007$ ), more likely to have been on holiday the previous year (vegetarian forty-five of fifty subjects, omnivores thirty-six of fifty subjects; $P=0.049$ ) and a little less likely to be from a family that owned a car (vegetarians twenty-nine of fifty subjects, omnivores thirty-eight of fifty subjects; $P=0.06$ ).

The main food sources of energy, protein, carbohydrate, NSP and fat are shown in Table 2 , together with the weight of a variety of foods consumed. The vegetarians did not eat much larger amounts of fruit, vegetables or dairy products, but consumed over twice the amount of vegetarian convenience products and high-fibre breakfast cereals (vegetarians $24 \mathrm{~g}$, omnivores $11 \mathrm{~g}$ ) and less soft drinks. The total amount of bread consumed was similar, but the vegetarians consumed more wholemeal bread ( $39 \mathrm{~g})$ than omnivores $(18 \mathrm{~g})$.

\section{Macronutrient intake}

The energy intake of the vegetarians was a little below that of the omnivores, but intakes of both groups were comparable with UK national values (Department of Health, 1989; Table 3) and estimated average requirements (EAR) (Table 5). BMR of the vegetarians and omnivores were similar: 4.70 (SE 0.78) and 4.74 (SE 0.08) $\mathrm{MJ} / \mathrm{d}$ respectively, $P=0.56$. Energy intake: BMR ratios for the vegetarians and omnivores were also similar: vegetarian 1.63 (SE 0.34), omnivore 1.71 (SE 0.04); $P=0.10$. The protein intake (expressed both in $\mathrm{g}$ and relative to energy intake) of the omnivores was significantly higher than that of the vegetarians, but both groups met the RNI. The vegetarian group had a similar intake of carbohydrate overall to that of the omnivores but consumed less sugars. The NSP intake 
Table 2. Food sources of macronutrients and NSP (\%) and weights of some foods consumed by 7-11-year-old matched pairs of vegetarian $(V)$ and omnivore $(O)$ children from the Liverpool area*

\begin{tabular}{|c|c|c|c|c|c|c|c|c|c|c|c|c|}
\hline & \multicolumn{2}{|c|}{ Energy } & \multicolumn{2}{|c|}{ Fat } & \multicolumn{2}{|c|}{ Protein } & \multicolumn{2}{|c|}{ Carbohydrate } & \multicolumn{2}{|c|}{ NSP } & \multicolumn{2}{|c|}{$\begin{array}{l}\text { Wt of food } \\
(\mathrm{g} / \mathrm{d})\end{array}$} \\
\hline & o & $\mathrm{V}$ & 0 & $\mathrm{~V}$ & 0 & V & 0 & $\mathrm{~V}$ & $\mathrm{O}$ & V & $\mathrm{O}$ & V \\
\hline Beans & $1 \cdot 4$ & 1.0 & $0 \cdot 1$ & 0.2 & $1 \cdot 4$ & $2 \cdot 4$ & 0.94 & 0.04 & 5.9 & 7.0 & 17 & 24 \\
\hline Bread & $9 \cdot 0$ & $9 \cdot 1$ & $2 \cdot 4$ & $2 \cdot 3$ & $12 \cdot 3$ & $15 \cdot 6$ & $16 \cdot 4$ & 16.5 & $18 \cdot 8$ & $19 \cdot 0$ & 84 & 82 \\
\hline Cakes, puddings and biscuits & $14 \cdot 3$ & $13 \cdot 3$ & $14 \cdot 6$ & $16 \cdot 1$ & $7 \cdot 3$ & $7 \cdot 0$ & $20 \cdot 5$ & $23 \cdot 0$ & $5 \cdot 4$ & $5 \cdot 1$ & 83 & 102 \\
\hline Cereals & 7.5 & $9 \cdot 6$ & 0.7 & $1 \cdot 4$ & $5 \cdot 0$ & 6.6 & 5.7 & $7 \cdot 0$ & $14 \cdot 0$ & $14 \cdot 6$ & 41 & 41 \\
\hline Cheese & 3.9 & $2 \cdot 6$ & 5.5 & 8.0 & $5 \cdot 0$ & $9 \cdot 0$ & 0.02 & 0.04 & 0.0 & 0.0 & 13 & 21 \\
\hline Chips & 5.5 & 3.9 & $4 \cdot 8$ & $4 \cdot 4$ & $3 \cdot 6$ & $2 \cdot 4$ & $9 \cdot 7$ & 5.0 & $9 \cdot 7$ & $5 \cdot 1$ & 40 & 30 \\
\hline Confectionery & 6.9 & $6 \cdot 9$ & $6 \cdot 3$ & 6.7 & $2 \cdot 2$ & $2 \cdot 5$ & $16 \cdot 1$ & 14.9 & $\dagger$ & + & 35 & 31 \\
\hline Convenience vegetarian foods & 0.6 & $2 \cdot 8$ & 1.0 & 6.5 & $1 \cdot 5$ & $4 \cdot 0$ & 0.1 & 0.2 & 3.6 & $4 \cdot 6$ & 21 & 59 \\
\hline Crisps & 5.5 & $5 \cdot 3$ & $9 \cdot 1$ & 9.0 & 1.5 & 1.7 & $7 \cdot 7$ & 5.8 & 7.7 & 5.6 & 19 & 20 \\
\hline Dairy products & $9 \cdot 2$ & $13 \cdot 0$ & 14.9 & $15 \cdot 7$ & 14.9 & 14.8 & $10 \cdot 1$ & $15 \cdot 1$ & $0 \cdot 0$ & 0.0 & 177 & 187 \\
\hline Fish & $1 \cdot 4$ & $0 \cdot 3$ & $1 \cdot 1$ & 1.0 & $4 \cdot 7$ & $3 \cdot 0$ & 0.4 & 0.3 & $0 \cdot 0$ & 0.0 & 23 & 5 \\
\hline Fruit & 1.5 & $2 \cdot 1$ & $0 \cdot 1$ & $0 \cdot 1$ & 0.6 & $1 \cdot 0$ & $5 \cdot 7$ & $8 \cdot 5$ & $7 \cdot 0$ & 6.8 & 50 & 66 \\
\hline Meat and meat products & $12 \cdot 3$ & $0 \cdot 0$ & $20 \cdot 0$ & 0.0 & $30 \cdot 4$ & $0 \cdot 0$ & 2.6 & 0.0 & 0.0 & 0.0 & 88 & 0 \\
\hline Nuts and peanut butter & $1 \cdot 0$ & $2 \cdot 1$ & $2 \cdot 1$ & $4 \cdot 1$ & $1 \cdot 1$ & $2 \cdot 5$ & 0.1 & $0 \cdot 3$ & 0.9 & $2 \cdot 2$ & 3 & 5 \\
\hline Oil & 0.3 & 1.5 & 0.9 & $3 \cdot 4$ & $\ddagger$ & $\ddagger$ & 0.0 & 0.0 & 0.0 & 0.0 & $0 \cdot 6$ & 3 \\
\hline Salad dressing & 0.3 & 0.5 & 1.5 & 1.0 & 0.02 & 0.04 & 0.03 & 0.03 & $0 \cdot 0$ & 0.0 & 0.8 & 1.6 \\
\hline Soft drinks & $5 \cdot 4$ & $4 \cdot 2$ & 0.1 & $0 \cdot 1$ & 0.6 & $0 \cdot 1$ & $22 \cdot 0$ & $18 \cdot 5$ & $0 \cdot 0$ & 0.0 & 123 & 90 \\
\hline Spreading fats & 4.8 & 4.8 & $13 \cdot 3$ & $13 \cdot 1$ & 0.2 & 0.3 & 0.04 & 0.04 & $0 \cdot 0$ & 0.0 & 13 & 14 \\
\hline Table sugar & 1.5 & 0.6 & 0.0 & 0.0 & 0.0 & 0.0 & 6.8 & 29 & 0.0 & 0.0 & 7 & 3 \\
\hline Vegetables & $3 \cdot 4$ & 5.4 & $2 \cdot 8$ & $3 \cdot 1$ & 1.5 & $4 \cdot 0$ & $18 \cdot 0$ & 20.0 & $18 \cdot 3$ & $20 \cdot 0$ & 92 & 108 \\
\hline
\end{tabular}

* For details of subjects and procedures, see pp. 534-535.

$\dagger$ Food tables incomplete.

$\ddagger<0.01 \%$.

of the vegetarians was significantly higher than that of the omnivores. There was no difference in fat intake (expressed in $g$ or percentage of energy intake) between the two groups. The fat intake of the omnivores was slightly lower than that of the national sample. The vegetarians consumed less saturated $(S)$ and monosaturated fats and significantly more polyunsaturated (P) fats than the omnivores, giving them a higher $P: S$ ratio. Meat contributed $20 \%$ of the fat intake of the omnivores, but the vegetarians consumed more fat from oil, dairy products and convenience vegetarian foods (Table 2).

\section{Minerals}

The Ca intake of the vegetarians was significantly higher than that of the omnivores, but both groups met the RNI (Tables 4 and 5). The main sources of $\mathrm{Ca}$ in the vegetarians' diet compared with those of the omnivores' diet were (\%): dairy products $33 \cdot 3 v .34 \cdot 5$, cheese $14.4 v .11 \cdot 0$, and cakes, biscuits and puddings $8 \cdot 0$ v. 9.0.

There was no difference in the $\mathrm{Fe}$ intake between the two groups and both groups met the RNI (Tables 4 and 5). The omnivores obtained $15 \cdot 3 \%$ of their Fe from meat and meat products but all the Fe consumed by the vegetarian group was from non-haem sources. The main sources of $\mathrm{Fe}$ in the vegetarian group compared with those of the omnivore group were (\%): breakfast cereals $25 \cdot 1$ v. 24.5 , bread $23.7 v .16 .2$, cakes, biscuits and puddings 8.4 v. 4.6 , vegetables 7.9 v. 6.0 , chips $2.8 v .4 .6$ and convenience vegetarian products $4 \cdot 4$ v. $1 \cdot 4$. 
Table 3. Comparison of intakes of macronutrients and NSP for 7-11-year-old matched pairs of vegetarian and omnivore children from the Liverpool area*

(Mean values with their standard errors for fifty subjects)

\begin{tabular}{|c|c|c|c|c|c|c|}
\hline & \multicolumn{2}{|c|}{ Omnivore } & \multicolumn{2}{|c|}{ Vegetarian } & \multirow{2}{*}{$\begin{array}{c}\text { Statistical } \\
\text { significance } \\
\text { of difference: } P\end{array}$} & \multirow{2}{*}{$\begin{array}{c}\text { National } \\
\text { (Department of } \\
\text { Health, 1989) }\end{array}$} \\
\hline & Mean & $\mathrm{SE}$ & Mean & SE & & \\
\hline Energy $(\mathrm{kJ})$ & 8039 & $193 \cdot 3$ & 7595 & $148 \cdot 2$ & 0.052 & 8088 \\
\hline Protein: $\mathrm{g}$ & $59 \cdot 4$ & 1.49 & $49 \cdot 8$ & $1 \cdot 32$ & 0.00 & $57 \cdot 1$ \\
\hline$\%$ Energy intake & $12 \cdot 6$ & 0.21 & $11 \cdot 1$ & 0.20 & 0.00 & $12 \cdot 0$ \\
\hline Carbohydrate: $\mathrm{g}$ & $256 \cdot 6$ & $7 \cdot 0$ & $248 \cdot 8$ & $5 \cdot 13$ & $0 \cdot 32$ & $255 \cdot 0$ \\
\hline$\%$ Energy intake & $51 \cdot 0$ & 0.53 & $52 \cdot 5$ & 0.57 & $0-69$ & $50 \cdot 5$ \\
\hline Sugars (g) & $113 \cdot 9$ & $4 \cdot 0$ & $103 \cdot 7$ & $3 \cdot 3$ & 0.046 & $\dagger$ \\
\hline NSP $(g)$ & $10 \cdot 3$ & 0.43 & $13 \cdot 8$ & 0.71 & 0.00 & $\dagger$ \\
\hline Fat: $\mathrm{g}$ & $79 \cdot 2$ & $2 \cdot 19$ & $74 \cdot 9$ & 1.97 & $0 \cdot 16$ & $82 \cdot 0$ \\
\hline$\%$ Energy intake & $36 \cdot 5$ & 0.46 & $36 \cdot 4$ & 0.55 & 0.94 & $37 \cdot 5$ \\
\hline $\begin{array}{l}\text { Saturated fat (S) } \\
\quad \text { (\% energy intake) }\end{array}$ & $12 \cdot 7$ & $0 \cdot 35$ & $13 \cdot 4$ & 0.25 & $0 \cdot 136$ & $\dagger$ \\
\hline $\begin{array}{l}\text { Polyunsaturated fat }(\mathrm{P}) \\
\quad(\% \text { energy intake) }\end{array}$ & $6 \cdot 6$ & $0 \cdot 20$ & $8 \cdot 0$ & 0.26 & $0 \cdot 00$ & $\dagger$ \\
\hline $\begin{array}{l}\text { Monounsaturated fat } \\
\text { (\% energy intake) }\end{array}$ & $11 \cdot 7$ & $0 \cdot 20$ & $11 \cdot 1$ & 0.02 & $0 \cdot 048$ & + \\
\hline$P: S$ & 0.5 & 0.02 & 0.7 & 0.04 & $0 \cdot 00$ & $\dagger$ \\
\hline Cholesterol (mg) & 184 & $7 \cdot 8$ & 132 & 8.5 & $0 \cdot 00$ & $\dagger$ \\
\hline
\end{tabular}

* For details of subjects and procedures, see pp. 534-535.

$\dagger$ No value given.

$\mathrm{Zn}$ intake of the vegetarians was lower than that of the omnivores and both groups had average intakes below the RNI (Tables 4 and 5). Six vegetarian and six omnivorous children had $\mathrm{Zn}$ intakes below the LRNI (Table 5). Meat contributed $34.6 \%$ of the omnivores' $\mathrm{Zn}$ intake. Other sources of $\mathrm{Zn}$ in the vegetarian group compared with those of the omnivore group were $(\%)$ : breakfast cereals $10.3 v .6 \cdot 1$, bread $16.8 v .10 \cdot 5$, cakes, biscuits and puddings $6 \cdot 0 v$. 5.0, vegetables $10.6 v .7 \cdot 2$, dairy products $20.7 v$. $14 \cdot 5$, eggs $1 \cdot 8$ v. $0 \cdot 4$, nuts $2 \cdot 8 v \cdot 0 \cdot 7$, and convenience vegetarian products $6 \cdot 4 v .3 \cdot 6$.

\section{Vitamins}

There was no statistically significant difference in the intake of total retinol equivalents between the two groups, which both met the RNI. The vegetarians, however, consumed more carotene but retinol intakes were similar. In the omnivores' diet meat contributed $10.7 \%$ to the intake of retinol equivalents. The main sources of retinol equivalents in the vegetarian diet compared with those of the omnivore diet were (\%): dairy products $19.7 \mathrm{v}$. $24 \cdot 8$, vegetables 34.4 v. $21 \cdot 8$ and margarine $19 \cdot 2$ v. $21 \cdot 3$. The vitamins $E$ and $D$ intakes of the vegetarians were higher than those of the omnivores. The main sources of vitamin $D$ in the vegetarian and omnivore groups were foods fortified with the vitamin (\%): breakfast cereals $21 \cdot 6$ v. $24 \cdot 3$ and margarine and butter $35 \cdot 1$ v. $36 \cdot 4$.

The thiamin and folic acid intakes of the vegetarians were higher than those of the omnivores. The main sources of thiamin in the vegetarian and omnivore diets were respectively $(\%)$ : cereals $26.6 v .26 .6$, bread $16.3 v .14 .3$ and vegetables $15.4 v .16 .9$. The niacin and vitamin $B_{12}$ intakes of the vegetarians were lower than those of the omnivores but met the appropriate RNI (Table 5). There was no difference in the mean vitamin $\mathrm{C}$ intakes between the two groups. The main sources of vitamin $\mathrm{C}$ in the vegetarian and 
Table 4. Comparison of intakes of micronutrients for 7-11-year-old matched pairs of vegetarian and omnivore children from the Liverpool area*

(Mean values with their standard errors for fifty subjects)

\begin{tabular}{|c|c|c|c|c|c|c|}
\hline & \multicolumn{2}{|c|}{ Omnivore } & \multicolumn{2}{|c|}{ Vegetarian } & \multirow{2}{*}{$\begin{array}{c}\text { Statistical } \\
\text { significance } \\
\text { of difference: } P\end{array}$} & \multirow{2}{*}{$\begin{array}{c}\text { National } \\
\text { (Department of } \\
\text { Health, 1989) }\end{array}$} \\
\hline & Mean & SE & Mean & SE & & \\
\hline $\mathrm{Ca}$ (mg) & 737 & $26 \cdot 1$ & 825 & $25 \cdot 87$ & 0.016 & $760 \cdot 4$ \\
\hline $\mathrm{Fe}(\mathrm{mg})$ & 10.6 & 0.34 & $11 \cdot 2$ & 0.42 & 0.28 & $9 \cdot 23$ \\
\hline $\mathrm{Mg}(\mathrm{mg})$ & 210 & 5.9 & 243 & $9 \cdot 2$ & 0.002 & $\dagger$ \\
\hline $\mathrm{Zn}(\mathrm{mg})$ & 6.8 & 0.22 & $5 \cdot 9$ & $0 \cdot 20$ & 0.001 & + \\
\hline Carotene $(\mu \mathrm{g})$ & 1164 & 95 & 1771 & 156 & 0.000 & 1463 \\
\hline Retinol $(\mu \mathrm{g})$ & 379 & $41 \cdot 2$ & 359 & 16.7 & 0.657 & 528 \\
\hline Retinol equivalent $(\mu \mathrm{g})$ & 602 & 45.8 & 684 & $29 \cdot 3$ & $0 \cdot 128$ & 776 \\
\hline Vitamin $\mathrm{D}(\mu \mathrm{g})$ & $2 \cdot 2$ & $0 \cdot 11$ & $2 \cdot 6$ & $0 \cdot 13$ & 0.011 & 1.44 \\
\hline Vitamin E (mg) & $4 \cdot 4$ & 0.21 & $5 \cdot 6$ & 0.42 & 0.019 & $\dagger$ \\
\hline Riboflavin $(\mu \mathrm{g})$ & 1.6 & 0.08 & 1.7 & 0.07 & 0.673 & 1.58 \\
\hline Thiamin (mg) & 1.4 & 0.05 & $1 \cdot 7$ & $0 \cdot 18$ & 0.098 & $1 \cdot 14$ \\
\hline Niacin (mg) & 16.9 & 0.66 & $14 \cdot 9$ & 0.59 & $0-028$ & $1 \cdot 14$ \\
\hline Pyridoxine (mg) & 1.7 & 0.07 & $1 \cdot 7$ & 0.06 & 0.926 & $1 \cdot 11$ \\
\hline Vitamin $\mathrm{B}_{12}(\mu \mathrm{g})$ & 3.4 & 0.22 & $2 \cdot 5$ & $0 \cdot 13$ & 0.00 & $\dagger$ \\
\hline Folate $(\mu \mathrm{g})$ & 214 & $9 \cdot 6$ & 238 & $8 \cdot 6$ & 0.045 & + \\
\hline Vitamin C (mg) & 63.9 & $4 \cdot 36$ & $66 \cdot 1$ & 3.95 & 0.71 & 43.89 \\
\hline
\end{tabular}

* For details of subjects and procedures, see pp. 534-535.

† No value given.

Table 5. Nutrient intakes of 7-11-year-old matched pairs of vegetarian and omnivore children from the Liverpool area* compared with reference nutrient intake ( $R N I$; Department of Health, 1991)

(Mean values and standard deviations for fifty subjects)

\begin{tabular}{|c|c|c|c|c|c|c|c|c|}
\hline \multirow[b]{3}{*}{ Nutrients } & \multicolumn{4}{|c|}{ Intake ( $\%$ RNI) } & \multirow{2}{*}{\multicolumn{2}{|c|}{$\begin{array}{c}\text { Percentage of subjects } \\
<\text { RNI }\end{array}$}} & \multirow{2}{*}{\multicolumn{2}{|c|}{$\begin{array}{c}\text { Percentage of subjects } \\
<\text { LRNI }\end{array}$}} \\
\hline & \multicolumn{2}{|c|}{ Omnivores } & \multicolumn{2}{|c|}{ Vegetarians } & & & & \\
\hline & Mean & SD & Mean & SD & Omnivores & Vegetarians & Omnivores & Vegetarians \\
\hline Energy $\dagger$ & 103 & $16 \cdot 5$ & 98 & $13 \cdot 8$ & - & - & - & - \\
\hline Protein & 201 & 57.2 & 198 & $49 \cdot 2$ & 1 & 0 & 0 & 0 \\
\hline Thiamin & 197 & $49 \cdot 6$ & 239 & $181 \cdot 4$ & 0 & 0 & 0 & 0 \\
\hline Niacin & 140 & $38 \cdot 8$ & 124 & $34 \cdot 6$ & 12 & 18 & 0 & 4 \\
\hline Riboflavin & 161 & $58 \cdot 0$ & 165 & $47 \cdot 9$ & 12 & 8 & 0 & 0 \\
\hline Pyridoxine & 165 & $49 \cdot 2$ & 165 & $42 \cdot 2$ & 2 & 2 & 0 & 0 \\
\hline Vitamin $B_{12}$ & 329 & $148 \cdot \overline{3}$ & 247 & $95 \cdot 0$ & 2 & 2 & 0 & 2 \\
\hline Folate & 107 & $34 \cdot 0$ & 119 & $30 \cdot 3$ & 44 & 34 & 0 & 0 \\
\hline Vitamin $\mathrm{C}$ & 206 & $105 \cdot 0$ & 218 & $94 \cdot 8$ & 14 & 8 & 0 & 0 \\
\hline Retinol equivalent & 109 & $54 \cdot 7$ & 137 & $40 \cdot 7$ & 58 & 20 & 0 & 0 \\
\hline $\mathrm{Ca}$ & 126 & $39 \cdot 0$ & 146 & $35 \cdot 5$ & 28 & 14 & 4 & 0 \\
\hline $\mathrm{Mg}$ & 101 & $21 \cdot 0$ & 119 & $32 \cdot 4$ & 52 & 28 & 0 & 0 \\
\hline $\mathrm{Fe}$ & 120 & $27 \cdot 9$ & 126 & 36.5 & 28 & 18 & 4 & 2 \\
\hline $\mathbf{K}$ & 107 & $24 \cdot 5$ & 110 & $21 \cdot 4$ & 38 & 26 & 0 & 0 \\
\hline $\mathrm{Zn}$ & 94 & $20 \cdot 6$ & 84 & 20.4 & 62 & 80 & 6 & 6 \\
\hline
\end{tabular}

* For details of subjects and procedures, see pp. 534-535.

$\uparrow$ Energy as a proportion of estimated average requirement. 
omnivore diets were respectively (\%): vegetables $26 \cdot 8 v .23 \cdot 9$, fruit $17 \cdot 4 v .13 \cdot 8$, fruit juice $33 \cdot 1$ v. $34 \cdot 6$ and cordials $9 \cdot 6$ v. $14 \cdot 4$.

\section{Blood tests}

Seventy-nine measurements of haemoglobin were made which included thirty-five matched pairs. The mean haemoglobin (g/l) level of the thirty-five vegetarians (118.6 (SE 1.8)) was lower $(P=0 \cdot 036)$ than that of the matched omnivores (124.1 (SE 2.0)). In comparison with the Dallman \& Siimes (1979) reference curves, $33.0 \%$ of the omnivores (thirteen of thirtynine subjects) and $47.5 \%$ of the vegetarians (nineteen of forty) fell below the 3rd percentile (less than 11.6, 11.7, 11.8, 11.9 and 12.0 in girls and less than 11.4, 11.6, 11.7, 11.8 and 12.0 in boys for children aged 7,8,9,10 and 11 years respectively). The proportions of vegetarians and omnivores falling below the 3 rd percentile were similar $(P>0.05)$.

Seventy-six cholesterol measurements were taken which included thirty-two matched pairs. The cholesterol levels $(\mathrm{mmol} / \mathrm{l})$ of the matched pairs were similar: vegetarian $3 \cdot 51$ (SE 0.12), omnivore 3.68 (SE 0.15);P=0.28. One vegetarian and four omnivorous children ( $n$ 76) had cholesterol levels above $4.8 \mathrm{mmol} / 1$, a value agreed with the Ethical Committee to trigger referral to their family doctors for further assessment.

\section{DISCUSSION}

Most of the vegetarians were recruited through their schools and none through the Vegetarian Society. The majority of studies of vegetarians have recruited subjects from Vegetarian or Vegan societies or other groups well educated regarding a vegetarian diet. This is then the first study of English school-aged pre-adolescent 'independent ' vegetarians.

Vegetarian groups may differ from omnivores in various ways; some are reluctant to use medical services and may refuse to allow their children to be vaccinated (Sanders \& Manning, 1992) or take vitamin and mineral supplements (Jacobs \& Dwyer, 1988), whilst others live health-orientated lifestyles (Beeson et al. 1989). However, in the present study the omnivorous and vegetarian groups were closely matched for age, sex, ethnic group, socio-economic factors and health-related behaviour. It was hoped, therefore, that the study was controlled for a wide variety of factors which may affect dietary intake.

Mean measured energy intake (MEI):BMR, has been used as an indication of the validity of dietary methods (Bingham, 1987). A ratio below 1.4 suggests gross underreporting or a change in dietary habits for the period of recording (Bingham, 1987). Values of 1.71 and 1.63 for the omnivores and vegetarians in the present study are slightly higher than those previously reported (1.5-1.57 for 11-12 year old children; Adamson et al. 1992), which suggests that gross under-reporting did not occur.

A larger number of the sample were female and more were from higher socio-economic groups. This is similar to the distribution of vegetarians in the population nationally (Leatherhead Food Research Association, 1993). About $8 \%$ of people aged 11-18 years are vegetarian (Vegetarian Society, 1991), yet little is known about how diets change on becoming vegetarian. This is especially important in those who are about to experience maximal growth and high nutrient requirements.

Both the omnivores and the vegetarians met the EAR for energy, although the energy intake of the vegetarians was a little lower. This is consistent with earlier reports (Hardinge $\&$ Stare, 1954). Vegetarians replaced meat with milk, cheese, beans, convenience vegetarian foods and eggs and not with large amounts of fruit and vegetables. This suggests that convenience remained a major factor in food choice. The vegetarians also consumed less sugars and a larger proportion of their sugars in cakes, biscuits and jam but less in drinks, on cereals and as confectionery, fruit juices and squashes. The combined effect of a lower 
intake of sugars consumed with other foods and a lower intake of sugary snack items is likely to be beneficial to the dental health of the vegetarians.

The tendency for vegetarians to consume similar amounts of fat to omnivores but to have a higher $\mathrm{P}: \mathrm{S}$ ratio has been reported in adult vegetarians in the UK (Draper et al. 1993; Thorogood et al. 1994). Adolescent SDA children (aged 16 years) were reported to obtain only $33 \%$ of their energy from fat, but a similar amount from saturated fat $(12 \%)$ to that of the vegetarians in the present study. The fat intake of both omnivores and vegetarians was lower than that reported for 11-12-year-old Northumbrian children (39-40\%; Adamson et al. 1992). Social class influences dietary intake (Adamson, 1993) and the fact that $52 \%$ of children in the present study were from high social classes may account for the slightly lower fat intake. The vegetarians obtained an appreciable amount of fat from convenience vegetarian products, the market for which has trebled in 5 years (Leatherhead Food Research Association, 1993). There may be a misconception amongst the public that vegetarian products are low in fat. There certainly appears to be a gap in this market for low-fat convenience vegetarian foods that appeal to children.

The vegetarians had a similar mean cholesterol level to that of the omnivores. A significant difference may develop with age since Thorogood et al. (1987) reported that the total cholesterol concentrations of adult vegetarians were lower than those of omnivores. The number of children with cholesterol levels above $4.8 \mathrm{mmol} / 1$ was comparable with that of a pilot study in Liverpool which found five of eighty-five children (5.8\%) to have levels above $4.9 \mathrm{mmol} / \mathrm{l}$ (Austin et al. 1991). At this stage, therefore, a vegetarian diet was not strongly associated with lower cholesterol levels.

For the vegetarians the RNI for Ca was easily met by the higher consumption of dairy products, but the problems of comparing mineral intakes of vegetarians with recommended values have been outlined (Gibson, 1994). For children, dietary reference values (DRV) for $\mathrm{Zn}$ are calculated by assuming a percentage absorption of $\mathrm{Zn}$ of 30 , but in a plant-based diet it may be as low as $15 \%$ (Sandström, 1989). In vegetarian diets high levels of phytic acid, NSP and $\mathrm{Ca}$ and low levels of animal protein may reduce $\mathrm{Zn}$ bioavailability. Vegetarian children may be at greater risk of sub-optimal $\mathrm{Zn}$ status than adults due to their greater requirements for growth and their failure to adapt to a vegetarian diet by increasing absorption (Gibson, 1994). Sub-optimal $\mathrm{Zn}$ deficiency has been reported in children following largely plant-based diets (Smit-Vanderkooy \& Gibson, 1987), but there are no data on the $\mathrm{Zn}$ status of vegetarian children in the UK. The mean $\mathrm{Zn}$ intakes of both groups of children were generally below those reported for children in the UK, Canada and USA (Gibson, 1994).

The Fe intake of the vegetarians was similar to that of the meat-eaters, but haemoglobin levels were lower, presumably because the vegetarians consumed non-haem-Fe. Nearly half the vegetarian children and one-third of omnivores were below the 3rd percentile for haemoglobin. This is greater than the percentage $(23 \%)$ found in a sample of vegetarian girls (aged 11-14 years) in London (Nelson et al. 1994). In addition, the prevalence of anaemia was reported to be more than twice as common in vegetarians $(25 \%)$ compared with omnivores $(9 \%)$, and concern has been expressed also regarding the incidence of anaemia among healthy middle-class white children generally (Nelson et al. 1993). The present study supports the view that the Fe status of children, and especially vegetarian children, warrants urgent further investigation (Nelson et al. 1993).

It was surprising that the vitamin $C$ intake of the vegetarians was not higher than that of the omnivores. This was because the vegetarians ate only slightly more fruit and vegetables, but the omnivores consumed larger amounts of blackcurrant juice drink and fruit juices. Both groups had intakes greater than the nationwide sample (Department of Health, 1989) and well above the RNI. In a non-vegetarian, approximately $100 \mathrm{~g}$ meat may 
have the same effect on non-haem-Fe absorption as $75 \mathrm{mg}$ vitamin C (Baynes \& Bothwell, 1990), suggesting the need for even higher vitamin C intakes in vegetarians. Vegetarians should be encouraged to consume extra fruit, which contain organic acids in addition to ascorbic acid (Ballot et al. 1987).

The vitamin $B_{12}$ intake was adequate because dairy products were consumed. The only vegan's intake was below the LRNI, emphasizing that care is required by vegans to ensure an adequate vitamin $B_{12}$ intake and that supplements are essential.

The NSP intake of the vegetarians was considerably higher than that of the meat-eaters, mainly due to the consumption of high-fibre breakfast cereals and wholemeal bread rather than larger quantities of fruits and vegetables. The current recommendation for adults is $18 \mathrm{~g} / \mathrm{d}$ (Department of Health, 1991). Using the DRV for energy of 19-50-year-old men a recommended intake of $1.7 \mathrm{~g} \mathrm{NSP} / \mathrm{MJ}$ can be calculated. Hence, a recommended intake of $12.9 \mathrm{~g}$ for the vegetarian children and $13.7 \mathrm{~g}$ for the omnivores was calculated. Only the vegetarians achieved this.

The present study suggests that the diet of vegetarian children more closely resembled dietary recommendations (Department of Health, 1991) than that of a group of matched meat-eaters. On average their diet was higher in NSP, lower in sugars, and had a higher P:S ratio. It is suggested, however, that vegetarians take particular care to ensure an adequate $\mathrm{Fe}$ intake, although the $\mathrm{Fe}$ status of all children requires further investigation. In addition, the vegetarians consumed a similar proportion of their energy as 'fat' to that of the omnivores and, therefore, need to be as vigilant as those who eat meat to reduce their intake of fat in line with current recommendations (Department of Health, 1994). The importance for a vegetarian diet to be varied and well planned in order to meet nutritional requirements, particularly for minerals, cannot be overstated. Substitution of commonly available convenience vegetarian products for meat is not adequate.

The present work was supported in part by a grant from the Vegetarian Society of the UK.

\section{REFERENCES}

Adamson, A. (1993). Nutrient intakes (1990 with 1980) and place of purchase of foods (1990) by 11 to 12 year old Northumbrian children. PhD Thesis, University of Newcastle upon Tyne.

Adamson, A., Rugg-Gunn, A., Butler, T., Appleton, D. \& Hackett, A. F. (1992). Nutritional intake, height and weight of 11-12-year-old Northumbrian children in 1990 compared with information obtained in 1980 . British Journal of Nutrition 68, 543-563.

American Dietetic Association (1988). Position of the American Dietetic Association : vegetarian diets. Journal of the American Dietetic Association 93 (11) 1317-1319.

Austin, R. P., Foy, G., Smith, M. J., Martin, I., Favell, H. \& Davidson, D. C. (1991). Pilot study testing feasibility of screening for hyperlipidaemia at school entrance medical. Proceedings of the 63rd Annual Meeting of the British Paediatric Association, p. 71, G120 Abstr. London: British Paediatric Association.

Ballot, D., Baynes, R. D., Bothwell, T. H., Gillooly, M., MacFarlane, B. J., MacPhail, A. P., Lyons, G., Derman, D. P., Bezwoda, W. R., Torrance, J. D., Bothwell, J. E. \& Mayet, F. (1987). The effects of fruit juices and fruits on the absorption of iron from a rice meal. British Journal of Nutrition 57, 331-343.

Baynes, R. D. \& Bothwell, T. H. (1990). Iron deficiency. Annual Review of Nutrition 10, 133-148.

Beeson, W. L., Mills, P. K., Phillips, R. L., Andress, M. \& Fraser, G. E. (1989). Chronic disease among seventhday adventists a low-risk group. Cancer 64, 570-581.

Bingham, S. A. (1987). The dietary assessment of individuals, methods, accuracy, new techniques and recommendations. Nutrition Abstracts and Reviews 57, 705-742.

British Dietetic Association (1995). Position Paper: Vegetarian Diets. Birmingham: BDA.

Curtis, J. A., Whay Kooh, S., Fraser, D. \& Greenberg, M. L. (1983). Nutritional rickets in vegetarian children. Canadian Medical Association Journal 128, 150-152.

Dagnelie, P. C., Van Staveren, W. A., Vergote, F. J. V. R. A., Dingjan, P. G., Vanden Berg, H. \& Hauvast, J. G. A. J. (1989). Increased risk of vitamin $\mathrm{B}_{12}$ and iron deficiency in infants on macrobiotic diets. American Journal of Clinical Nutrition 50, 818-824.

Dallman, P. R. \& Siimes, M. A. (1979). Percentile curves for hemoglobin and red cell volume in infancy and childhood. Journal of Pediatrics 94, 26-31. 
Department of Health (1989). The Diets of British Schoolchildren. Report on Health and Social Subjects no. 36. London: H.M. Stationery Office.

Department of Health (1991). Dietary Reference Values for Food Energy and Nutrients For the United Kingdom. Report on Health and Social Subjects no. 41. London: H.M. Stationery Office.

Department of Health (1994). Nutritional Aspects of Cardiovascular Disease. Report on Health and Social Subjects no. 46. London: H.M. Stationery Office.

Draper, A., Lewis, J., Malhotra, N. \& Wheeler, E. (1993). The energy and nutrient intakes of different types of vegetarian: a case for supplements? British Journal of Nutrition 69, 3-19.

Dwyer, J. T., Dietz, W. H., Andrews, E. M. \& Sistind, R. M. (1982). Nutritional status of vegetarian children. American Journal of Clinical Nutrition 35, 204-216.

Dwyer, J. T., Dietz, W. H., Hass, G. \& Suskind, R. (1979). Risk of nutritional rickets among vegetarian children. American Journal of Diseases in Childhood 133, 134-140.

Gibson, R. S. (1994). Content and bioavailability of trace elements in vegetarian diets. American Journal of Clinical Nutrition 59, Suppl., 1223S-1232S.

Hackett, A. F., Rugg-Gunn, A. J. \& Appleton, D. R. (1983). Use of dietary diary and interview to estimate the food intake of children. Human Nutrition: Applied Nutrition 37A, 293-300.

Hardinge, M. G. \& Stare, F. J. (1954). Nutritional studies of vegetarians 1. Nutritional, physical and laboratory studies. American Journal of Clinical Nutrition 2, 73-82.

Hellebostad, M., Markestad, T. \& Seeger Halvorsen, K. (1985). Vitamin D deficiency rickets and vitamin B $_{12}$ deficiency in vegetarian children. Acta Paediatrica Scandinavica 74, 191-195.

Holland, B., Unwin, I. D. \& Buss, D. H. (1988). Third Supplement to McCance and Widdowson's The Composition of Foods, 4th ed. Cereals and Cereal Products. Cambridge: Royal Society of Chemistry.

Holland, B., Unwin, I. D. \& Buss, D.H. (1989). Fourth Supplement to McCance and Widdowson's The Composition of Foods, 4th ed. Milk Products and Eggs. Cambridge: Royal Society of Chemistry.

Holland, B., Unwin, I. D. \& Buss, D. H. (1991 a). Fifth Supplement to McCance and Widdowson's The Composition of Foods, 4th edn. Vegetables, Herbs and Spices. Cambridge: Royal Society of Chemistry.

Holland, B., Welch, A. A. \& Buss, D. H. (1992a). First Supplement to McCance and Widdowson's The Composition of Foods, 5th edn. Fruit and Nuts. Cambridge: Royal Society of Chemistry.

Holland, B., Welch, A. A. \& Buss, D. H. (1992b). Second Supplement to McCance and Widdowson's The Composition of Foods, 5th edn. Vegetable Dishes. Cambridge: Royal Society of Chemistry.

Holland, B., Welch, A. A., Unwin, I. D., Buss, D. H., Paul, A. A. \& Southgate, D. A. T. (1991 b). McCance and Widdowson's The Composition of Foods, 5th edn. Cambridge: Royal Society of Chemistry.

Jacobs, C. \& Dwyer, J. T. (1988). Vegetarian children: appropriate and inappropriate diets. American Journal of Clinical Nutrition 48, 811-818.

Kaplan, R. M. \& Toshima, M. T. (1992). Does a reduced fat diet cause retardation in child growth? Preventative Medicine 21, 33-52.

Leatherhead Food Research Association (1993). The UK Vegetarian Food Report. Industry and Market Reviews no. 15, pp. 133-135. Leatherhead: Leatherhead Food Research Association.

Maclean, W. C. \& Graham, G. G. (1980). Vegetarianism in children. American Journal of Diseases in Childhood 134, 513-519.

Moynihan, P. J., Butler, T. J. \& Rugg-Gunn, A. J. (1995). Determination of energy intake in 7-10 year old children: use of a food record and interview technique. Proceedings of the Nutrition Society 53, $254 \mathrm{~A}$.

Nelson, M., Bakaliou, F. \& Trivedi, A. (1994). Iron-deficiency anaemia and physical performance in adolescent girls from different ethnic backgrounds. British Journal of Nutrition 72, 427-433.

Nelson, M., White, J. \& Rhodes, C. (1993). Haemoglobin, ferritin and iron intakes in British children aged 12-14 years: a preliminary investigation. British Journal of Nutrition 70, 147-155.

Registrar General (1991). Office of Population Censuses and Surveys, Classification of Occupations, 1991. London: H.M. Stationery Office.

Roberts Fulton, J., Hutton, C. W. \& Stitt, K. R. (1980). Preschool vegetarian children. Journal of the American Dietetic Association 76, 360-365.

Sabate, J., Linsted, K. D., Harris, R. D. \& Sanchez, A. (1991). Attained height of lacto-ovo vegetarian children and adolescents. European Journal of Clinical Nutrition 45, 51-58.

Sanders, T. A. B. \& Manning, J. (1992). The growth and development of vegan children. Journal of Human Nutrition and Dietetics 5, 11-21.

Sandström, B. (1989). Dietary patterns and zinc supply. In Zinc in Human Biology, pp. 351-363 [C. F. Mills, editor]. New York: Springer-Verlag.

Schofield, W. N., Schofield, C. \& James, W. P. T. (1985). Basal metabolic rate-review and prediction. Human Nutrition: Clinical Nutrition 39, Suppl., 1-96.

Smit-Vanderkooy, P. D. \& Gibson, R. S. (1987). Food consumption patterns of Canadian children in relation to zinc and growth status. American Journal of Clinical Nutrition 45, 609-616.

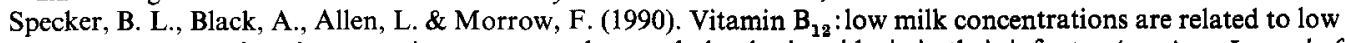
serum concentrations in vegetarian women and to methylmalonic aciduria in their infants. American Journal of Clinical Nutrition 52, 1073-1076. 
Statistical Package for Social Sciences (1993). Base Manual V4.0. Chicago, Ill: SPSS Inc.

Tan, S. P., Wenlock, R. W. \& Buss, D. H. (1985). Second Supplement to McCance and Widdowson's The Composition of Foods, 4th ed. Immigrant Foods. London: H.M. Stationery Office.

Thorogood, M., Carter, R., Benfield, L., McPherson, K. \& Mann, J. I. (1987). Plasma lipids and lipoprotein cholesterol concentrations in people with different diets in Britain. British Medical Journal 295, 351-353.

Thorogood, M., Mann, J., Appleby, P. \& McPherson, K. (1994). Risk of death from cancer and ischaemic heart disease in meat and non-meat eaters. British Medical Journal 308, 1667-1670.

University of Salford (1993). Microdiet 8.08. Salford: University of Salford.

Van Staveren, W. A. \& Dagnelie, P. C. (1988). Food consumption, growth, and development of Dutch children fed on alternative diets. American Journal of Clinical Nutrition 48, 819-821.

Vegetarian Society (1991). Trends in Vegetarianism Amongst Adults and Young People. Altrincham: Vegetarian Society. 